\title{
Parent and Friend Influences on the Multiple Health Behaviors of Adolescents in Hawai i
}

\author{
Karly S. Geller ${ }^{1}$, Antonia R. Alvarez ${ }^{2,3}$, Claudio R. Nigg ${ }^{3,4}$, Aaron Oasay ${ }^{2}$, and Jerson \\ Timbobolan ${ }^{2}$ \\ ${ }^{1}$ Miami University, Department of Kinesiology $\&{ }^{2}$ University of Hawai i Cancer Center, \\ Prevention and Control \\ ${ }^{3}$ Mental Health America of Hawai $i$ \\ ${ }^{4}$ University of Hawai $i$ at Mānoa, Public Health Sciences
}

\begin{abstract}
Background and Purpose: The prevalence of youth obesity has increased dramatically in the United States, becoming a severe concern in Hawai $\mathrm{i}$ and disproportionally impacting Filipino youth. The main study objective was to describe the influence of parents and friends on adolescents' dietary, physical activity, and sedentary behaviors. Methods: We collected quantitative and qualitative data from two classrooms in Hawai $\mathrm{i}$, from ethnic minority adolescents $\left(\mathrm{N}=42 ; 11^{\text {th }}\right.$ and $12^{\text {th }}$ graders $)$ and their parents $(\mathrm{N}=31)$. Participating adolescents were $86 \%$ female with a mean age of $16.5 \pm .6$ years, and their parents were $77 \%$ female with a mean age of $45.9 \pm 6.9$ years. The majority of participants described themselves as Filipino American. Self-report data were collected via adolescent surveys and follow-up group discussion, as well as individual adolescent-led parent interviews. Quantitative data were descriptive, and qualitative data were conceptualized into underlying themes based on the targeted health behavior and the source of influence (parents and friends). Results: The majority of students reported parents as the dominant influence on their dietary and sedentary behaviors; however, friends were reported as the principal influence on adolescents' physical activity levels. Parents' reported a strong dietary influence via home availability, but minimal influence on adolescents' physical activity. Conclusion: Home food availability and reduced television time are prime targets for family-based interventions among ethnic minority Hawai ian populations.
\end{abstract}

(C) 2014 Californian Journal of Health Promotion. All rights reserved.

Keywords: Adolescents, Hawai `ian, Filipino, obesity, physical activity, nutrition

\section{Introduction}

There has been a dramatic rise in the prevalence of youth obesity in the United States (US) (Ogden, Carroll, Curtin, Lamb, \& Flegal, 2010), demonstrating strong association with adverse health outcomes (Daniels, 2006) and healthrelated costs. Specifically, annual obesity-related hospital costs increased from \$35 million (19791981) to $\$ 127$ million (1997-1999) (Wang \& Dietz, 2002).

Obesity is largely a consequence of energy imbalance generating from increased energy intake and/or decreased energy expenditure, with relation to dietary habits (Nicklas, Yang,
Baranowski, Zakeri, \& Berenson, 2003), physical activity, and sedentary behavior (Berkey, Rockett, Gillman, \& Colditz, 2003; Janssen, Katzmarzyk, Boyce, Vereecken, Mulvihill, et al., 2005). Similar to mainland populations, Hawai ian and Pacific Islander youth typically report high fat intake and low fruit and vegetable consumption (Moy, Sallis, \& David, 2010). Research targeting all US adolescents reported only 8\% perform enough physical activity to experience health benefits (Troiano, Berrigan, Dodd, Masse, Tilert, et al., 2008), and inactivity rates are lowest among ethnic minority youth (Javier, Huffman, \& Mendoza, 2007; Tudor-Locke, Ainsworth, Adair, \& Popkin, 2003). Although less than two 
daily hours of screen time is recommended (American Academy of Pediatrics, 2011), 32\% of youth reported watching television for three or more hours on a regular school day and $31 \%$ used the computer for three or more hours (Eaton, Kann, Kinchen, Shanklin, Flint, et al., 2012).

\section{Obesity-related Disparities in Hawai'i}

Using multiple anthropometric assessments, approximately $24 \%$ of adolescents residing in Hawai i (aged 12-17 years) were classified as obese; compared to $11 \%$ of adolescents (aged 12-19 years) reported via NHANES III statistics (Chai, Kaluhiokalani, Little, Hetzler, Zhang, et al., 2003). Asian-Americans are among the fastest growing ethnic minority population in the US (United States Census Bureau, 2009), representing a multitude of diverse subgroups (e.g., Japanese, Filipinos). Although Asians are traditionally identified as a homogeneous population (Ye, Rust, Baltrus, \& Daniels, 2009), the health disparities encountered across Asian origins are highly variable. For example, Filipino individuals are more likely to develop hypertension compared to their Asian counterparts, and Filipino youth demonstrate greater risk of developing obesity and related illnesses (Baruffi, Hardy, Waslien, Uyehara, \& Krupitsky, 2004; Grandinetti, Chang, Theriault, \& Mor, 2005; Ye et al., 2009).

Effective health promotion for diverse youth requires initial knowledge of valued cultural components of virtue (e.g., food, social relationships, etc.) (Braun \& Nichols, 1997; Finucane \& McMullen, 2008); yet, few interventions do more than add cultural references to existing curricula (McGrath \& Ka'ili, 2010). To inform appropriately tailored intervention efforts for youth residing in Hawai $i$, in-depth examinations are a necessary preliminary step to better understand existing enablers and barriers to healthy lifestyles.

\section{Parent and Peer Influences on Adolescent Obesity-related Behaviors}

Research suggests that both parents and friends influence youth eating and physical activity (Duncan, Duncan, \& Strycker, 2005; McClain, Chappius, Nguyen-Rodriquez, Yaroch, \&
Spruijt-Metz, 2009; O’Dea, 2003; Pugliese \& Tinsley, 2007; Prochaska, Rodgers, \& Sallis, 2002). However, evidence regarding the relative influences of parents and peers on adolescent behaviors are inconsistent. Recent research suggests friends are more influential than parents on youth physical activity (Finnerty, Reeves, Dabinett, Jeanes, \& Vogele, 2009; Heitzler, Lytle, Erickson, Barr-Anderson, Sirard \& Story, 2010). In another study of adolescent females, parents support for physical activity decreased, while friends' support increased over time (Davison \& Jago, 2009). Furthermore, family involvement with youth was negatively associated with youth television time, relative to friend involvement (Springer, Kelder, \& Hoelscher, 2006); another study reported similar associations (Richards, McGee, Williams, Welch, \& Hancox, 2010). In their review of dietary-related influences, Geller and Dzewaltowski (2009) found peers having an additive influence on adolescents' fruit and vegetable intake rather than a parent replacement, suggesting a significant parental influence that continues across adolescent development.

\section{The Present Study}

The current study was a quantitative and qualitative inquiry of the obesity-related health behaviors shared between Hawai $i$ residing adolescents and their parent. Self-report data were collected via adolescent surveys and follow-up group discussion, as well as individual adolescent-led parent interviews. The general objective was to explore the perceived influence of parents and friends on adolescents' obesity-related behaviors; specifically assessing adolescents' reported shared time with parents and friends and their motivation to change their obesity-related behaviors. The predominantly Filipino youth sample provided the opportunity to generate initial understanding of certain social factors influencing the multiple health behaviors of an understudied Asian-American population living in Hawai i.

Given high variability in parent supervision and monitoring of youth across cultures and levels of socioeconomic status and education (Li, Feigelman, \& Stanton, 2000), data collection 
also included parents' perceived influence on their adolescents' obesity-related behavior. In addition to serving as a potential catalyst for future health conversations, this youth-led research approach facilitated a gateway to the home environment. Such youth involvement contributes to tailored intervention efforts while simultaneously expanding participating adolescents' knowledge and skills, increasing their capacity to engage in healthy behaviors (Suleiman, Soleimanpour, \& London, 2006). Youth-led research has been published previously among Native Hawai ian adolescents (Geller, Hendricks, Alvarez, Braceros, \& Nigg, 2013). Participating adolescents were expected to report both parent and friend shared time; and, given youth remain dependent on the resources within their home environment, a strong parental influence was expected to emerge for all targeted health behaviors.

\section{Methods}

\section{Participants and Setting}

Informed consent preceded all study procedures, which were approved by the University Institutional Review Board and the State of Hawai i Department of Education. Participating adolescents $(\mathrm{N}=42)$ were $11^{\text {th }}$ and $12^{\text {th }}$ grade high school students residing in Oahu, Hawai i. Through a university-teacher partnership, students were recruited from two separate high school classrooms. Participating students elicited the participation of one of their parents, resulting in a $74 \%$ parent response rate $(\mathrm{N}=31$ parent participants); which is comparable to research among similar youth populations (e.g., Geller, et al., 2013). All participating adolescents were born in the US, majority in Hawai $i$. The immigrant status of adolescents' parents was variable, with most born in Hawai i. Given limited classroom time, this information was collected unsystematically via hand count of participating adolescents.

The school was located in a highly populated city with a predominantly Filipino-American population and a median household income of $\$ 49,444$; which is comparable to national levels (\$51, 914), but considerably lower than the state of Hawai i (\$63, 030) (US Census Bureau,
2010). During the 2010/11 school year, the high school student population was primarily Filipino-American (65.5\%) followed by Samoan (9.3\%), part-Hawai ian (6.5\%), and other or mixed ethnicities (18.7\%). Forty-nine percent of students were included in the free/reduced school lunch program during that same year, which was slightly higher than the average Hawaìi public high school at $47 \%$ (Hawai i State Department of Education, 2010).

\section{Procedure}

Student Survey and Interview._Adolescent data were derived via self-reported surveys with follow-up class-level discussions. Adolescent self-report surveys included quantitative questions, as well as open-ended (i.e., qualitative) questions; which assessed demographic characteristics and certain health behaviors shared with their parent and friends. Following survey completion, a trained focus group moderator led participating adolescents in a follow-up classroom discussion to review each survey question. All adolescents who completed the student survey also participated in the follow-up group discussion, which was implemented in each classroom separately $(n=20$ and $n=22$ ). This qualitative follow-up approach supported clarity of survey questions, allowing adolescents to elucidate their initial answers further when appropriate.

Adolescent Interview of Parents. In preparation for subsequent adolescent-led parent interviews, adolescents participated in a 30minute training session that covered general research interview techniques. Specifically, adolescents were trained to distinguish between divergent and convergent questions; led through a brief discussion of each parent interview question; and organized into small groups to practice asking questions aloud, summarizing answers, and capturing direct quotes. Similar to adolescent surveys, parents were asked to selfreport certain demographic and health information, including personal behavior, shared behavior, and perceived parental influence. Specifically, adolescents led their mother or father through open-ended questions, summarized their parents' responses, and recorded enriching quotations. Parent interviews 
were mostly performed at home (98\%), lasting approximately 24 minutes ( \pm 14 minutes) and ranging from 8 to 63 minutes.

\section{Measures}

Adolescent Survey. Participating adolescents reported their gender, birthdate, and ethnicity. Quantitatively, adolescents also self-reported shared health-related time with their participating parent and friends, including shared meals ("How many meals per day do you eat with your parent? How about with your friends?"), shared television time ("How many times hours per day do you watch television or movies with your parent? How about with your friends?"), and shared computer time ("How many hours per day do you play video games or surf the Internet (e.g., Facebook) with your parent? How about with your friends?"). Adolescents were also asked to report weekly physical activity shared with their parent and friends ("How many times per week do you do physical activity (e.g., sports, gym workouts) with your parent? How about with your friends?"). Physical activity was initially defined to participating adolescents as an activity in which "you are moving your arms and legs fast enough to sweat or get your heart rate up. Physical activities include time spent walking, running, swimming, sports, surfing, mowing the lawn, etc."

Adolescents also reported shared time qualitatively via open-ended survey questions. For parents and friends, participating adolescents reported the types of foods shared ("What foods do you usually eat with your parents? How about with your friends?”), as well as types of physical activities shared ("What physical activities do you usually share with your parents? How about with your friends?). Finally, adolescents were asked about previous changes to their physical activity ("Have you previously changed your level of physical activity? Why, Why not?”), and dietary behaviors ("Have you previously changed your diet? Why, Why not?”).

Parent Interview._Parent interview start and stop times were recorded by adolescents and summarized as the average length of parent interviews (minutes). Parents were first asked to report their gender, birthdate, ethnicity, and relationship to the adolescent interviewer. Using the physical activity definition, participating adolescents defined physical activity for their parent and asked them to report their personal weekly frequency ("Aside from work and/or house chores, how many times per week do you engage in physical activity, like exercise or sports?”). Parents then reported their daily sedentary time ("How many hours per day do you do activities that are sedentary or not active?”). Finally, participating parents reported their perceived influence on their adolescent's physical activity ("Do you influence the physical activities I do? How, why not?"), and dietary behaviors ("Do you influence the foods I eat? How, why not?”).

\section{Data Analysis}

Quantitative data from both adolescents and parents were analyzed descriptively, including calculations of means and percentages. Adolescents' report of health-related time spent with parents and friends were averaged across the sample by gender, as was parents' self-report of personal health behavior. Participants' responses to open-ended questions were analyzed qualitatively, including the conceptualization of common themes by question and/or health behavior. Given the directive nature of open-ended questions, a content analysis approach was used to systematically analyze the content of participants' qualitative responses (Duncan, 1989). A color-coded key was used to categorize participants' open-ended reports into common themes, which were then rank-ordered by frequency. Response frequencies were then used to calculate the proportion of adolescent responses within common themes via the ratio $\mathrm{n}^{\mathrm{T}} / \mathrm{n}^{\mathrm{p}}$, where $\mathrm{n}^{\mathrm{T}}=$ the number of participants reporting within the common theme and $n^{\mathrm{p}}=$ the number of participants who offered a qualitative response.

\section{Results}

Participants' demographic characteristics are provided in Table 1. Participating adolescents $(\mathrm{N}=42)$ were $86 \%$ female with a mean age of 
$16.5( \pm 0.6)$, and their parents $(\mathrm{N}=31)$ were $77 \%$ female (i.e., mothers) with a mean age of 45.9 ( \pm 6.9). Similar to the high school population at the time of data collection, adolescents were $86 \%$ Filipino $(n=36), 5 \%$ Japanese $(n=2)$, $2 \%$ other Asian ( $\mathrm{n}=1), 2 \%$ Tongan $(\mathrm{n}=1), 2 \%$ Samoan $(n=1)$, and $2 \%$ White $(n=1)$. Parents were $82 \%$ Filipino ( $n=26)$, 10\% Japanese $(n=3)$, 3\% White $(n=1)$, and $3 \%$ Samoan $(n=1)$. Aside from one father and son, all participating adolescents selfidentified as the same ethnicity as their parent.

\section{Table 1.}

Demographic and Adolescents' Shared Health Behavior

\begin{tabular}{|c|c|c|c|c|c|c|c|c|}
\hline & \multicolumn{4}{|c|}{ Adolescents } & \multicolumn{4}{|c|}{ Parents } \\
\hline & \multicolumn{2}{|c|}{$\begin{array}{c}\text { Males } \\
\mathrm{n}=6(17 \%) \\
\end{array}$} & \multicolumn{2}{|c|}{$\begin{array}{c}\text { Female } \\
\mathrm{n}=35(83 \%)\end{array}$} & \multicolumn{2}{|c|}{$\begin{array}{c}\text { Fathers } \\
\mathrm{n}=7(30 \%)\end{array}$} & \multicolumn{2}{|c|}{$\begin{array}{c}\text { Mothers } \\
\mathrm{n}=24(70 \%)\end{array}$} \\
\hline Ethnicity & \multicolumn{2}{|c|}{ n (\%) } & \multicolumn{2}{|c|}{ n (\%) } & \multicolumn{2}{|c|}{ n (\%) } & \multicolumn{2}{|c|}{ n (\%) } \\
\hline Filipino American & \multicolumn{2}{|c|}{$4(66 \%)$} & \multicolumn{2}{|c|}{32 (89\%) } & \multicolumn{2}{|c|}{$5(71 \%)$} & \multicolumn{2}{|c|}{$21(88 \%)$} \\
\hline Japanese American & \multicolumn{2}{|c|}{$1(17 \%)$} & \multicolumn{2}{|c|}{$1(3 \%)$} & \multicolumn{2}{|c|}{$2(29 \%)$} & \multicolumn{2}{|c|}{$1(4 \%)$} \\
\hline Caucasian & \multicolumn{2}{|c|}{--} & \multicolumn{2}{|c|}{$1(3 \%)$} & & & \multicolumn{2}{|c|}{$1(4 \%)$} \\
\hline Samoan & \multicolumn{2}{|c|}{-} & \multicolumn{2}{|c|}{$1(3 \%)$} & \multicolumn{2}{|c|}{-} & \multicolumn{2}{|c|}{$1(4 \%)$} \\
\hline Tongan & \multicolumn{2}{|c|}{$1(17 \%)$} & \multicolumn{2}{|c|}{-} & \multicolumn{2}{|c|}{-} & \multicolumn{2}{|c|}{-} \\
\hline \multirow[t]{4}{*}{ Mean Age, Years (SD) } & \multicolumn{2}{|c|}{$16.50(0.55)$} & \multicolumn{2}{|c|}{$16.47(0.56)$} & \multicolumn{2}{|c|}{$48.86(8.59)$} & \multicolumn{2}{|c|}{$45.05(6.24)$} \\
\hline & \multicolumn{4}{|c|}{ Male Adolescents } & \multicolumn{4}{|c|}{ Female Adolescents } \\
\hline & \multicolumn{2}{|c|}{$\begin{array}{l}\text { Parent- } \\
\text { shared }\end{array}$} & $\begin{array}{l}\text { Frie } \\
\text { sha }\end{array}$ & & $\begin{array}{l}\text { Pare } \\
\text { sha }\end{array}$ & & $\begin{array}{l}\text { Frie } \\
\text { sha }\end{array}$ & \\
\hline & Mean & SD & Mean & $\mathrm{SD}$ & Mean & SD & Mean & $\mathrm{SD}$ \\
\hline Daily Meals & 1.67 & 0.82 & 1.17 & 0.75 & 1.77 & 0.94 & 1.33 & 0.93 \\
\hline $\begin{array}{l}\text { Weekly Physical } \\
\text { Activity Bouts }\end{array}$ & 0.00 & 0.00 & 4.00 & 2.37 & 0.50 & 1.03 & 1.97 & 1.61 \\
\hline Daily Computer Hours & 0.00 & 0.00 & 2.00 & 2.28 & 0.63 & 1.21 & 2.37 & 2.50 \\
\hline $\begin{array}{l}\text { Daily TELEVISION } \\
\text { hours }\end{array}$ & 2.40 & 2.88 & 1.20 & 1.10 & 2.70 & 2.59 & 0.82 & 1.02 \\
\hline
\end{tabular}

\section{Adolescent Quantitative Outcomes}

Overall, most time was sedentary, while friendshared time was more conducive to physical activity. The average daily television hours shared with parents was threefold that shared with friends. Conversely, computer time with friends was more than double that shared with parents, generally including Internet-based networking (e.g., Facebook, Myspace). Adolescents reported sharing approximately two meals each day with their parent and one shared daily meal with their friends.

Quantitative results were interpreted more specifically by adolescent gender (see Table 1). Participating males reported no parent-shared shared physical activity or computer time; however, they shared just under $2 \frac{1}{2}$ hours of daily television time with their parents. Limited parent-shared time was also reported among female adolescents; specifically, physical activity was shared less than once per week and daily shared computer time was reported under one hour. Similar to male reports, participating females reported over $2 \frac{1}{2}$ hours of shared television time their parent each day. Both genders watched considerably less television with friends than parents, sharing approximately one hour each day with their friends. Adolescents also shared more physical activity time with friends than with their parent; male and female adolescents reported four and two 
friend-shared weekly bouts, respectively.

\section{Adolescent Qualitative Outcomes}

Table 2 summarizes adolescents' reports to open-ended survey questions, including common themes, response frequencies, and response proportions. Outcomes are organized in the following sections by each adolescent survey question.

What foods do you usually eat with your parents/friends? In general, parent-shared meals were more healthful and nutritious than the friend-shared meals reported (e.g., fruit and vegetables versus fast food). All participants reported eating "Filipino food" at home with their parents. Two commonly reported traditional Filipino dishes were Pinakbet and Adobo, containing vegetables and occasional meat. The majority of adolescents also reported parent-shared meals that typically included meat (pork, beef, chicken, and fish) and starch foods (mostly rice), as well as meals high in fruits and vegetables. Alternatively, adolescents reported eating mostly fast food/junk food with their friends and minimum fruit and vegetable intake.

Table 2.

Adolescent Survey Questions, Themes, and Quotes

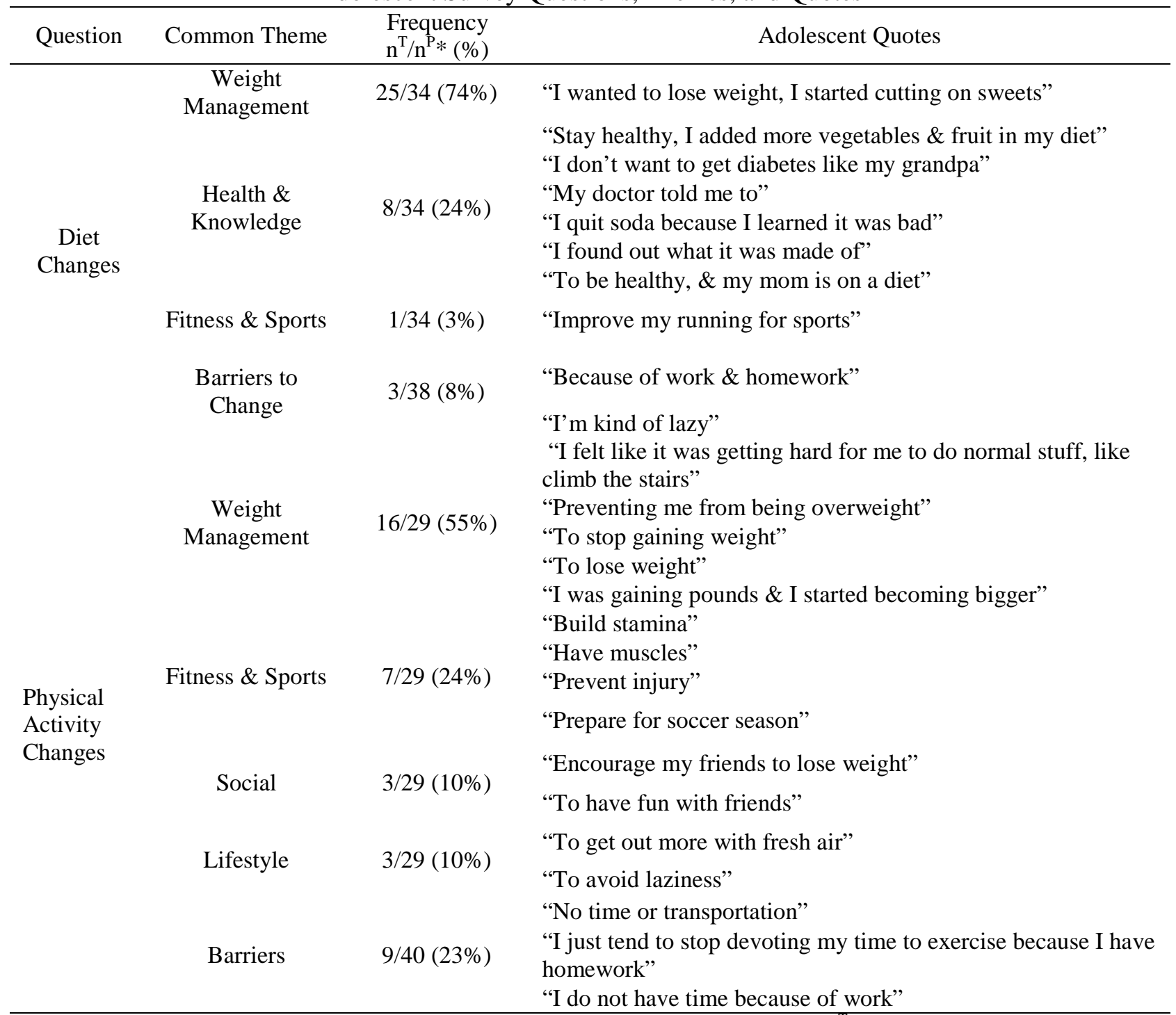

*Frequency is the number of participants who reported within the common theme $\left(\mathrm{n}^{\mathrm{T}}\right) /$ the number of participants 
who responded $\left(\mathrm{n}^{\mathrm{p}}\right)$.

What physical activities do you usually share with your parents/friends? The most frequently reported activities shared with parents were "nothing" and/or television watching. Adolescents reported a considerably larger variety of physical activity with their friends, most frequently reporting sport involvement and leisure activity (e.g., hanging out, walking to school, etc.).

Have you previously changed your diet? Why or Why not? Ninety percent of adolescents reported a previous change to their dietary behavior. Table 2 reports common themes and frequencies of qualitative reports. Participating adolescents most frequently reported weight loss and/or weight management motives for their previous diet-related change(s) $(\mathrm{n}=25,74 \%)$; which was followed by motivations related to health and knowledge $(\mathrm{n}=8,24 \%)$. Among adolescents who did not report previous changes to their diet $(10 \%), 8 \%(n=3)$ reported being "too lazy" or busy with school-related work.

Have you previously changed your level of physical activity? Why or Why not? The majority of adolescents (77\%) had previously changed their physical activity. Common themes and frequencies from qualitative reports are shown in Table 2. Similar to dietary changes, weight loss/management was the most commonly reported motive for previous changes to activity levels $(\mathrm{n}=16,55 \%)$. The second leading motive involved fitness and/or sport related goals $(n=7,24 \%)$, stating body image reasoning that echoed the nutrition context. Unique to physical activity were motivations for social interactions (e.g., "to have fun with friends") and lifestyle (e.g., "to be outside"). Among the 23\% adolescents reporting no prior change, all reported a lack of time for physical activity due work and/or school.

\section{Parent Quantitative Outcomes}

Specific to parent-reported health behavior, mothers participated in a bout of physical activity just over once per week $(\mathrm{M}=1.57 \pm$ 1.62) and fathers twice per week $(M=2.00 \pm$ 2.83). Mothers reported just over 3 hours of daily sedentary time $(\mathrm{M}=3.14 \pm 2.65)$, while fathers reported close to 4 hours of daily sedentary time $(\mathrm{M}=3.90 \pm 2.54)$.

\section{Parent Qualitative Outcomes}

Table 3 summarizes participating parents' openended responses regarding their perceived influence on adolescent health behavior, reporting frequencies and themes. Outcomes are organized in the following sections by each parent interview question.

Do you influence the foods I eat? How or why not? Eighty six percent of parents reported having an impact on their adolescent's dietary behavior, exclusively reporting food availability and accessibility as the mechanism of their influence. Among the $14 \%$ who did not recognize themselves as a dietary influence, $12 \%(n=4)$ reported adolescent consumption of meals outside of the home (e.g., "you always eat out”).

Do you influence the physical activities I do? How or why not? Sixty-one percent of parents believed they influence their adolescent's physical activity. Of those recognizing their influence, $64 \%(n=7)$ perceived themselves as a positive or negative role model. Thirty six percent of participating parents $(n=4)$ reported influencing their adolescent's physical activity through shared time ("We do mostly everything as a family"). Among parents who did not report having an influence (39\%), all reported time and/or fatigue related barriers.

\section{Discussion}

The current study aimed to distinguish between parent and friend influences on adolescents' dietary, sedentary, and physical activity behaviors. In general, results demonstrated variability between parent and friend influences on adolescent's obesity-related behavior. Similar to mainstream research, the meals shared between participating adolescents and their parent included more fruits and vegetables and less junk food than meals shared with friends. The healthier parent-shared meal supports evidence of healthier dietary patterns among youth exposed to more family meals (Berge, 
2009; Geller \& Dzewaltowski, 2009; Haapalahti, Mykkanen, Tikkanen, \& Kokkonen, 2003), and reports of increased snacking and fatty food intake when meals are shared with friends (Feunekes, de Graaf., Meyboom, \& van Staveren, 1998; Monge-Rojas, Nunez, Garita, \& Chen-Mok, 2002). The strong parent influence was evident ("you got to eat what's there, you don't have a choice"), similar to evidence among mainland American youth (McClain et al., 2009; Wansink, 2006) and family-based research among ethnic minority youth in Hawai i (Guerrero, Nishimura, Chang, Ona, Cunanan et al., 2010; McGrath \& Ka'ili, 2010). Taken together, home food availability and accessibility are leading influences on adolescents' dietary behaviors and should be prioritized in future intervention efforts.

\section{Table 3.}

Parent Interview Survey Questions, Themes, and Quotes

\begin{tabular}{|c|c|c|c|}
\hline Question & Common Theme & $\begin{array}{l}\text { Frequency } \\
{\left[\mathrm{n}^{\mathrm{T}} / \mathrm{n}^{\mathrm{P}}\right](\%)}\end{array}$ & Adolescent Quotes \\
\hline \multirow{6}{*}{ Diet } & \multirow{5}{*}{$\begin{array}{l}\text { Availability \& } \\
\text { Accessibility }\end{array}$} & \multirow{5}{*}{$22 / 22(100 \%)$} & $\begin{array}{l}\text { "Whenever you're home, you got to eat what's there, } \\
\text { you don't have a choice” } \\
\text { "I buy everything you eat" } \\
\text { "You got to eat what's there, you don't have a } \\
\text { choice” }\end{array}$ \\
\hline & & & "You eat what I give you, no complaining” \\
\hline & & & "Whatever I cook, you eat” \\
\hline & & & "We eat together as a family" \\
\hline & & & $\begin{array}{l}\text { "Because I told you it tastes good, \& you eat it" } \\
\text { "You eat whatever I cook" }\end{array}$ \\
\hline & Barriers to Influence & $4 / 34(12 \%)$ & "You always eat out" \\
\hline \multirow{7}{*}{$\begin{array}{l}\text { Physical } \\
\text { Activity }\end{array}$} & & & $\begin{array}{l}\text { "You bring junk food, \& eat out a lot" } \\
\text { "I think you want to be active so you won’t be } \\
\text { overweight like me" }\end{array}$ \\
\hline & Role modeling & $7 / 11(64 \%)$ & "I show what to do \& you do it" \\
\hline & & & "I don't do it [physical activity] myself" \\
\hline & \multirow{3}{*}{ Shared Activity } & \multirow{3}{*}{$4 / 11(36 \%)$} & "You come running with me” \\
\hline & & & "We do mostly everything as a family" \\
\hline & & & "You take me along with you” \\
\hline & Barriers to Influence & 14/31 (45\%) & $\begin{array}{l}\text { "Since I work } 5 \text { days a week, I’m too tired to go out } \\
\text { for a walk with you” } \\
\text { "I’m usually busy" } \\
\text { "You're barely home” } \\
\text { "I’m not always home, I couldn't influence you } \\
\text { unless I was home” }\end{array}$ \\
\hline
\end{tabular}

*Frequency is the number of participants who reported within the common theme $\left(\mathrm{n}^{\mathrm{T}}\right) /$ the number of participants who responded $\left(\mathrm{n}^{\mathrm{P}}\right)$.

Adolescents' dependency on parent food purchases and preparation was obvious in the current sample, which may be an effective direction for future promotional efforts. As dietary gatekeepers, parents contribute greatly to youth nutritional patterns by controlling food 
purchases and meal preparation. One strategic approach to promoting healthy food availability changes within the home environment is to drive intervention efforts through the participating youth (i.e., program action agents or vehicles to change). For example, research has examined empowerment strategies targeting youth efficacy to request healthier food options from their parents (Geller \& Dzewaltowski, 2010; Middlestadt, Lederer, Smith, Doss, Hung et al., 2013). Furthermore, previous intervention research has successfully promoted proxy efficacy to increase children's physical activity and related opportunities (Dzewaltowski, Estabrooks, \& Johnston, 2002; Dzewaltowski, Estabrooks, Welk, Hill, Milliken et al., 2009). Future investigations that build on these findings by evaluating similar efforts among youth in Hawai i are recommended.

Current results illuminated distinctions between the parent and friend influences on adolescents' physical activity and sedentary behaviors. Alike to several previous examinations, friend-related influences appeared to be more relevant to current adolescents' physical activity behavior (Finnerty et al., 2009; Heitzler et al., 2010). In a specific examination, youth biked a greater distance and demonstrated greater motivation to be physically active when a friend was present compared to when they were alone (Salvy, Roemmich, Bowker, Romero, Stadler et al., 2009); which parallels the high frequency of friend-shared physical activity bouts reported within the current adolescent sample.

On the other hand, parent-shared physical activity was rarely reported within the current sample and many parents did not perceive themselves as an influence on their adolescent's activity. Parents consistently reported work and time as barriers to their involvement; however, participating adolescents reported sharing approximately $2 \frac{1}{1} 2$ hours of television with their parent each day. This excessive parent-shared television time parallels previous research among conventional youth populations (Meizi, Harris, Piche', \& Beynon, 2009), and may be a prime target for future interventions. Future interventions are advised to target the substitution of shared family television time with activities that incorporate physical activity, such as after dinner family walks or sport activities.

Future research and promotional efforts among similar youth are advised to consider the shared time adolescents spend watching television and being active with their parents and friends. For example, time management strategies can guide the substitution of shared family television with activities incorporating physical activity (e.g., family walks, active games, etc.), which can be incorporated within the contextual nature of the home environment. For instance, the average US child lives in a home with access to a variety of screen time facilitators (televisions, video/DVD players, etc.) (Rideout, Vandewater, \& Wartella, 2003), which has been the most consistent correlate of adolescent television viewing (Gorely, Marshall, \& Biddle, 2004). Alternatively, the home environment can be adjusted to foster decreased television time via parental attitude (Meizi et al. 2009) and consistent parental rules (Norman, Schmid, Sallis, Calfas, \& Patrick, 2005).

Current adolescent also reported a commanding friend influence on their physical activity, which may be an advantageous avenue for future interventions. Specifically, promotional efforts targeting late-adolescent populations should capitalize on their motivations for autonomy by facilitating interactive physical activity opportunities among friend groups (e.g., sport teams, walking and jogging clubs, etc.). Participating adolescents' concern about their future health suggests the potential to promote health by increasing knowledge. Educating youth about the components and behaviors of a healthy diet is a collective responsibility (researchers, teachers, policy makers, etc.) and should be an educational priority. Considering most participating adolescents expressed body image concerns, it is strongly suggested that future interventions emphasize health-related outcomes, rather than motivations related to weight loss.

\section{Limitations}

Certain study limitations and strengths are noteworthy. The youth sample was relatively small, mostly female, and predominantly 
Filipino-American, limiting generalizability of study outcomes. In addition, study outcomes were based on participant self-report, introducing the risk for social desirability bias. Even so, this study is among the first multiple health behavior investigations among youth in Hawai i, providing valuable knowledge to advance future research among similar populations.

\section{Conclusion}

The social and physical environments surrounding $2^{\text {nd }} / 3^{\text {rd }}$ generation mainland youth are dramatically distinct from alike youth residing in Hawai $i$, an island thousands of miles from mainland America. The current manuscript is the first investigation of multiple health behaviors among Filipino-American youth, a population that will inevitably be designated high priority for public health research in the future (see US 2050 Census projections). One goal of Healthy People 2010 was to eliminate health disparities (USDHHS, 2000); however, evidence-based, culturally adapted interventions among Filipino youth in Hawaì remain severely warranted.
The current study is a preliminary step toward developing culturally appropriate interventions that aim to advance the health of similar ethnic minority populations. Similar to the current youth sample, television viewing represents the single greatest source of physical inactivity among US youth (Dietz \& Strasburger, 1991) and has a larger effect on obesity than activity and dietary behaviors alone (Saelens, Sallis, Nader, Broyles, Berry et al., 2002). Television has been shown to displace physical activity (Carlson, Fulton, Lee, Foley, Heitzler et al., 2010), facilitating an obesogenic home food environment comprised of mindless eating and increased energy intake (Rosenkranz \& Dzewaltowski, 2008). Reducing family-shared television time may create increased opportunities for physical activity and decreased risk of excessive energy consumption. A strong friend influence on adolescents' physical activity also emerged in the current study. Future interventions should target interactive physical activity opportunities between adolescents and their friends.

\section{Acknowledgements}

This study was funded by the National Cancer Institute, R25 CA90956 \& CURE Supplement, P30 CA071789

\section{References}

American Academy of Pediatrics, Committee on Public Education, American Academy of Pediatrics. (2011). Children, adolescents, and television. Pediatrics, 107, 423-426.

Anderson, J. N. (1983). Health and illness in Pilipino immigrants. The Western Journal of Medicine, 139(6), 811-819.

Baruffi, G., Hardy, C. J., Waslien, C. I., Uyehara, S. J., \& Krupitsky, D. (2004). Ethnic differences in the prevalence of overweight among young children in Hawai i. Journal of the American Dietetic Association, 104(11), 1701-1707.

Berge, J. M. (2009). A review of familial correlates of child and adolescent obesity: what has the $21^{\text {st }}$ century taught us so far? International Journal of Adolescent Medicine and Health, 21(4), 457483.

Berkey, C. S., Rockett, H. R., Gillman, M. W., \& Colditz, G. A. (2003). One-year changes in activity and in inactivity among 10- to 15-year-old boys and girls: relationship to change in body mass index. Pediatrics, 111, 836-843.

Braun, K. L., \& Nichols, R. (1997). Death and dying in four Asian American cultures: a descriptive study. Death Studies, 21(4), 327-359.

Campbell, K. J., Crawford, D. A., Salmon, J., Carver, A., Garnett, S. P., \& Baur, L. A. (2007). Associations between the home food environment and obesity-promoting eating behaviors in adolescence. Obesity, 15(3), 719-430.

Carlson, S. A., Fulton, J. E., Lee, S. M., Foley, J. T., Heitzler, C., \& Huhman, M. (2010). Influence of limit-setting and participation in physical activity on youth screen time. Pediatrics, 126, e89-96. 
Geller, K.S., Alvarez, A.R., Nigg,C.R., Oasay, A., Timbobolan, J. / Californian Journal of Health Promotion 2014, Volume 12, Issue 2, 55-68.

Chai, D., Kaluhiokalani, N., Little, J., Hetzler, R., Zhang, S., Mikami, J., \& Ho, K. (2003). Childhood overweight problem in a selected school district in Hawai i. American Journal of Human Biology, 15(2), 164-177.

Daniels, S. R. (2006). The consequences of childhood overweight and obesity. Future Child, 16, 47-67.

Davison, K. K., \& Jago, R. (2009). Change in parent and peer support across ages 9 to 15-years and adolescent girls' physical activity. Medicine and Science in Sports and Exercise, 41(9), 18161825.

Dietz, W. H., \& Strasburger, V. C. (1991). Children, adolescents, and television. Current Problems in Pediatrics, 21(1), 8-31.

Duncan, D. F. (1989). Content analysis in health education research: An introduction to purposes and methods. Health Education, 20(7), 27-31.

Duncan, S. C., Duncan, T. E., \& Strycker, L. A. (2005). Sources and types of social support in youth physical activity. Health Psychology, 24, 3-10

Dzewaltowski, D. A., Estabrooks, P. A., Welk, G., Hill, J., Milliken, G., Karteroliotis, K., \& Johnston, J. A. (2009). Healthy youth places: a randomized controlled trial to determine the effectiveness of facilitating adult and youth leaders to promote physical activity and fruit and vegetable consumption in middle schools. Health Education \& Behavior, 36(3), 583-600.

Dzewaltowski, D. A., Estabrooks, P. A., \& Johnston, J. A. (2002). Healthy youth places promoting nutrition and physical activity. Health Education Research, 17(5), 541-551.

Eaton, D. K., Kann, L., Kinchen, S., Shanklin, S., Flint, K.H., Hawkins, J., ... \& Lim, C. (2012). Youth risk behavior surveillance-United States, 2011. MMWR Surveillance Summaries, 61(4), 1162American Academy of Pediatrics, 2001)

Feunekes, G. I., de Graaf, C., Meyboom, S., \& van Staveren, W. A. (1998). Food choices and fat intake of adolescents and adults: associations of intakes within social networks. Preventative Medicine, 27, 645-656.

Finnerty, T., Reeves, S., Dabinett, J., Jeanes, Y. M., \& Vogele, C. (2009).Effects of peer influence on dietary intake and physical activity in schoolchildren. Public Health Nutrition, 13(3), 376-383.

Finucane, M. L., \& McMullen, C. K. (2008). Making diabetes self-management education culturally relevant for Filipino Americans in Hawai i. Diabetes Educator, 34(5), 841-853.

Geller, K. S., \& Dzewaltowski, D. A. (2009). Longitudinal and cross-sectional influences on youth fruit and vegetable consumption. Nutrition Reviews, 67(2), 65-76.

Geller, K. S., \& Dzewaltowski, D. A. (2010). Youth proxy efficacy for fruit and vegetable availability varies by gender and socio-economic status. Public Health Nutrition, 13(6), 843-851.

Geller, K. S., Hendricks, T. A., Alvarez, A. R., Braceros, K. C., \& Nigg, C. R. (2013). Parent and friend influences on the multiple health behavior of Pacific Islander adolescents. Health, 5(11B), 5-11.

Gorely, T. S., Marshall, S. J., \& Biddle, S. J. (2004). Couch kids: Correlates of television viewing among youth. International Journal of Behavioral Medicine, 11, 152-163.

Grandinetti, A., Chang, H. K., Theriault, A., \& Mor, J. (2005). Metabolic syndrome in a multiethnic population in rural Hawai i. Ethnicity and Disease, 15(2), 233-237.

Guerrero, A. P. S., Nishimura, S. T., Chang, J. Y., Ona, C., Cunanan, V. L., \& Hishinuma, E. S. (2010). Low cultural identification, low parental involvement and adverse peer influences as risk factors for delinquent behavior among Filipino youth in Hawai i. International Journal of Social Psychiatry, 56, 371-88.

Haapalahti, M., Mykkanen, H., Tikkanen, S., \& Kokkonen, J. (2003). Meal patterns and food use in 10- to 11-year-old Finnish children. Public Health Nutrition, 6, 365-370.

Hawai i State Department of Education. System Evaluation and Reporting Section, Systems Accountability Office, Office of the Superintendent November 22, 2010; Honolulu, HI.

Heitzler, C. D., Lytle, L. A., Erickson, D. J., Barr-Anderson, D., Sirard, J. R., \& Story, M. (2010). Evaluating a model of youth physical activity. American Journal of Health Behavior, 34(5), 593606.

Janssen, I., Katzmarzyk, P. T., Boyce, W. F., Vereecken, C., Mulvihill, C., Roberts, C., and Currie, C. 
Geller, K.S., Alvarez, A.R., Nigg,C.R., Oasay, A., Timbobolan, J. / Californian Journal of Health Promotion 2014, Volume 12, Issue 2, 55-68.

(2005). Health Behaviour in School-Aged Children Obesity Working Group. Comparison of overweight and obesity prevalence in school-aged youth from 34 countries and their relationships with physical activity and dietary patterns. Obesity Reviews, 6, 123-132.

Javier, J. R., Huffman, L. C., \& Mendoza, F. S. (2007). Filipino child health in the United States: Do health and health care disparities exist? Preventing Chronic Disease, 4(2). Available from: http://www.cdc.gov/pcd/issues/2007/apr/06_0069.htm.

Li, X., Feigelman, S., \& Stanton, B. (2000). Perceived parental monitoring and health risk behaviors among urban low-income African-American children and adolescents. Journal of Adolescent Health, 27(1), 43-48.

McClain, A. D., Chappius, C., Nguyen-Rodriquez, S. T., Yaroch, A. L., \& Spruijt-Metz. (2009). Psychosocial correlates of eating behavior in children and adolescents: A review. International Journal of Behavioral Nutrition and Physical Activity, 6(54), 1-20. doi: 10.1186/1479-5868-6-54

McGrath, B. B., \& Ka'ili T. O. (2010). Creating Project Talanoa: A culturally based community health program for US Pacific Islander adolescents. Public Health Nursing, 27(1), 17-24.

Meizi, H. M., Harris, S., Piche', L., \& Beynon, C. (2009). Understanding screen-related sedentary behavior and its contributing factors among school-aged children: A Social-Ecologic Exploration. American Journal of Health Promotion, 23(5), 299-308.

Middlestadt, S. E., Lederer, A. M., Smith, N. K., Doss, D., Hung, C. L., Stevenson, L. D., \& Fly, A. D. (2013). Determinants of middle-school students asking parents for fruits and vegetables: a theorybased salient belief elicitation. Public Health Nutrition, 16(11), 1971-1978.

Monge-Rojas, R., Nunez, H. P., Garita, C., \& Chen-Mok, M. (2002). Psychosocial aspects of Costa Rican adolescents' eating and physical activity patterns. Journal of Adolescent Health, 31, 212-219.

Moy, K. L., Sallis, J. F., \& David, K. J. (2010) Health indicators of Native Hawai ian and Pacific Islanders in the United States, Journal of Community Health, 35(1), 81-92

Nicklas, T. A., Yang, S. J., Baranowski, T., Zakeri, I., \& Berenson, G. (2003). Eating patterns and obesity in children: The Bogalusa Heart Study. American journal of preventive medicine, 25(1), 9-16.

Norman, G. J., Schmid, B. A., Sallis, J., Calfas, K. J., \& Patrick, K. (2005). Psychosocial and environmental correlates of adolescent sedentary behaviors. Pediatrics, 116(4), 908-916.

O’Dea, J. A. (2003). Why do kids eat healthful food? Perceived benefits of and barriers to healthful eating and physical activity among children and adolescents. Journal of the American Dietetic Association, 103, 497-501.

Ogden, C. L., Carroll, M. D., Curtin, L. R., Lamb, M. M., \& Flegal, K. M. (2010). Prevalence of high body mass index in US children and adolescents, 2007-2008. Journal of the American Medical Association, 303(3), 242-429.

Prochaska, J. J., Rodgers, M. W., \& Sallis, J. F. (2002). Association of parent and peer support with adolescent physical activity. Research Quarterly for Exercise and Sport, 73, 206-210.

Pugliese, J., \& Tinsley, B. (2007). Parental socialization of child and adolescent physical activity: A meta-analysis. Journal of Family Psychology, 21, 331-343.

Richards, R., McGee, R., Williams, S. M., Welch, D., \& Hancox, R. J. (2010). Adolescent screen time and attachment to parents and peers. Archives of Pediatrics \& Adolescent Medicine, 164(3), 258262.

Rideout, V. J., Vandewater, E. A., \& Wartella, E. A. (2003). Zero to Six: Electronic Media in the Lives of Infants, Toddlers and Preschoolers. Available at: http://eric.ed.gov/PDFS/ED482302.pdf. Accessed 15 March 2011.

Rosenkranz, R. R., \& Dzewaltowski, D. A. (2008). Model of the home food environment pertaining to childhood obesity. Nutrition reviews, 66(3), 123-140.

Saelens, B. E., Sallis, J. F., Nader, P. R., Broyles, S. L., Berry, C. C., \& Taras, H. L. (2002). Home environmental influences on children's television watching from early to middle childhood. Journal of Developmental \& Behavioral Pediatrics, 23(3), 127-132.

Salvy, S. J., Roemmich, J. N., Bowker, J. C., Romero, N. D., Stadler, P. J., \& Epstein L. H. (2009). Effect of peers and friends on youth physical activity and motivation to be physically active. Journal 
Geller, K.S., Alvarez, A.R., Nigg,C.R., Oasay, A., Timbobolan, J. / Californian Journal of Health Promotion 2014, Volume 12, Issue 2, 55-68.

Pediatric Psychology, 34(2), 2217-2225.

Singh, G. K., Kogan, M. D., \& Van Dyck, P. C. (2010). Changes in state-specific childhood obesity and overweight prevalence in the United States from 2003 to 2007. Archives of Pediatrics \& Adolescent Medicine, 164(7), 598-607.

Springer, A. E., Kelder, S. H., \& Hoelscher, D. M. (2006). Social support, physical activity and sedentary behavior among 6th-grade girls: a cross-sectional study. International Journal of Behavioral Nutrition and Physical Activity, 6, 8.

Stoddard, J. J., Back, M. R., \& Brotherton, S. E. (2000). The respective racial and ethnic diversity of US pediatricians and American children. Pediatrics, 105, 27-31.

Suleiman, A. B., Soleimanpour, S., \& London, J. (2006). Youth action for health through youth-led research. Journal of Community Practice, 14(1-2), 125-145.

Troiano, R. P., Berrigan, D., Dodd, K. W., Masse, L. C., Tilert, T., \& McDowell, M. (2008). Physical activity in the United States measured by accelerometer. Medicine and Science in Sports and Exercise, 40(1), 181-188.

Tudor-Locke, C., Ainsworth, B. E., Adair, L. S., \& Popkin, B. M. (2003). Physical activity in Filipino youth: The Cebu longitudinal health and nutrition survey. International Journal of Obesity, 27, 181-190.

U.S. Census Bureau. (2010). American Community Survey. http://www.census.gov/acs/www/

United States Department of Health and Human Services (USDHHS). (2000). Healthy People 2010 (conference edition, in two volumes). Washington, DC: US Government Printing Office.

Wang, G., \& Dietz, W. H. (2002). Economic burden of obesity in youths aged 6-17 years: 1979-1999. Pediatrics, 109, e81.

Wansink, B. (2006). Nutritional gatekeepers and the 72\% solution. Journal of the American Dietetic Association, 106, 1324-1327.

Wilson, D. K., \& Kitzman-Ulrich, H. (2008). Cultural considerations in the development of pediatric weight management programs. In E Jelalian, RG Steele (Eds.), Handbook of child and adolescent obesity, (pp. 293-310). New York: Springer Publishers.

Yasui, M., \& Dishion, T. J. (2007). The ethnic context of child and adolescent problem behavior: implications for child and family interventions. Clinical Child and Family Psychology Review, 10(2), 137-179.

Ye, J., Rust, G., Baltrus, P., \& Daniels, E. (2009). Cardiovascular risk factors among Asian Americans: results from a National Health Survey. Annals of Epidemiology, 19, 718-723.

Author Information

*Karly S Geller, PhD

Miami University

420 Oak Street, 120 Phillips Hall

Oxford Ohio, 45056

Tel: (513) 529-2702

Fax: (513) 529-5006

Email: gellerks@miamioh.edu

Antonia R. Alvarez MSW

University of Hawai i Cancer Center, Prevention and

Control

Mental Health America of Hawai`i

Claudio R. Nigg PhD

Mental Health America of Hawai $\mathrm{i}$

University of Hawai i at Mānoa, Public Health Sciences

Aaron Oasay 
Geller, K.S., Alvarez, A.R., Nigg,C.R., Oasay, A., Timbobolan, J. / Californian Journal of Health Promotion 2014, Volume 12, Issue 2, 55-68.

University of Hawai i Cancer Center, Prevention and Control

Jerson Timbobolan

University of Hawaì i Cancer Center, Prevention and Control

* corresponding author 